\title{
Design of real-time cow behavior monitoring system based on wireless sensor networks and K-Means clustering algorithm
}

Diseño de un sistema de monitoreo del comportamiento de vacas en tiempo real basado en redes de sensores inalámbricos y algoritmo de clustering de K-Means

\begin{abstract}
Projeto de um sistema de monitoramento do comportamento da vaca em tempo real com base em redes de sensores sem fio e algoritmo de agrupamento K-Means
\end{abstract}

\section{Duc-Nghia Tran ${ }^{1}$ \\ Thi-Thu Nguyen ${ }^{2}$ Duc-Tan Tran ${ }^{3}$}

Received: March $15^{\text {th }}, 2021$

Accepted: June $20^{\text {th }}, 2021$ Available: September $6^{\text {th }}, 2021$

How to cite this article:

T. Duc-Nghia, N. Thi-Thu, T. Duc-Tan, "Design of Real-Time Cow Behavior Monitoring System Based on Wireless Sensor Networks and K-Means Clustering Algorithm," Revista Ingeniería Solidaria, vol. 17, no. 3, 2021. doi: https://doi.org/10.16925/2357-6014.2021.03.11

Research article. https://doi.org/10.16925/2357-6014.2021.03.11

1 Institute of Information Technology (IOIT), Vietnam Academy of Science and Technology (VAST)

Email: nghiatd@ioit.ac.vn

ORCID: https://orcid.org/0000-0003-2457-2145

2 Faculty of Electronic Engineering, Hanoi University of Industry

Email: thunt@haui.edu.vn

ORCID: https://orcid.org/0000-0002-4396-4374

3 Faculty of Electrical and Electronic Engineering, Phenikaa University

Email: tan.tranduc@phenikaa-uni.edu.vn

ORCID: https://orcid.org/0000-0002-7673-388X 
2 Design of real-time cow behavior monitoring system based on wireless sensor networks and K-Mmeans clustering algorithm

\section{Abstract}

Introduction: The present article is the product of the research with reference code DLTE00.02/20-21. This work was supported by the Vietnam Academy of Science and Technology.

Problem: Animal monitoring is a significant problem in the agricultural sector. The primary purpose is to enable regular monitoring of the health of animals; the consequence of which could lead to improvements in animal welfare and product quality, with a marked increase in profit. Cow behavior recognition system was considered as the right solution for cow monitoring. The requirements for this kind of system are that it should be economical, high performance, and provide real-time data.

Objective: The research objective is to design a real-time cow monitoring system based on wireless sensor networks and the K-means clustering algorithm.

Methodology: A wireless sensor node was designed to measure the collar-mounted acceleration data using an accelerometer. Firstly, the collected data were classified into three classes based on the VeDBA (Vector of Dynamic Body Acceleration) feature using the K-means algorithm. Then, the thresholds for VeDBA in the previous step were used to classify new data.

Results: Three behaviors (including feeding, lying, and standing) were classified in real-time with the accuracy of classification in the region of $89 \%$.

Conclusion: The proposed system could be adapted to the monitoring of cows in real-time; the behavior classification could be implemented on the microcontroller. The results confirmed the reliability of the proposed system.

Originality: The behavior classification could be implemented on the microcontroller for the first time in cow monitoring.

Limitations: Only three behaviors were classified in the experiment.

Keywords: monitoring, sensor, K-means, wireless sensor networks, microcontroller

\section{Resumen}

Introducción: El presente artículo es producto de la investigación con código de referencia ĐLTE00.02 / 20-21. Este trabajo fue apoyado por la Academia de Ciencia y Tecnología de Vietnam.

Problema: El seguimiento de los animales es un problema importante en el sector agrícola. El objetivo principal es permitir un seguimiento regular de la salud de los animales; cuya consecuencia podría conducir a mejoras en el bienestar animal y la calidad del producto, con un marcado aumento de los beneficios. El sistema de reconocimiento del comportamiento de las vacas se consideró la solución adecuada para el seguimiento de las vacas. Los requisitos para este tipo de sistema son que sea económico, de alto rendimiento y proporcione datos en tiempo real.

Objetivo: El objetivo de la investigación es diseñar un sistema de monitoreo de vacas en tiempo real basado en redes de sensores inalámbricos y el algoritmo de agrupamiento K-means.

Metodología: Se diseñó un nodo sensor inalámbrico para medir los datos de aceleración montados en el collar usando un acelerómetro. En primer lugar, los datos recopilados se clasificaron en tres clases según la función VeDBA (Vector of Dynamic Body Acceleration) utilizando el algoritmo K-means. Luego, los umbrales para VeDBA en el paso anterior se utilizaron para clasificar nuevos datos.

Resultados: Se clasificaron tres comportamientos (que incluyen alimentarse, acostarse y pararse) en tiempo real con una precisión de clasificación en la región del $89 \%$. 
Conclusión: El sistema propuesto podría adaptarse al monitoreo de vacas en tiempo real; la clasificación de comportamiento podría implementarse en el microcontrolador. Los resultados confirmaron la fiabilidad del sistema propuesto.

Originalidad: La clasificación de comportamiento podría implementarse en el microcontrolador por primera vez en el monitoreo de vacas.

Limitaciones: solo se clasificaron tres comportamientos en el experimento.

Palabras clave: monitoreo, sensor, K-means, redes de sensores inalámbricos, microcontrolador

\section{Resumo}

Introdução: Este artigo é produto de uma pesquisa com o código de referência ĐLTE00.02 / 20-21. Este trabalho foi apoiado pela Academia de Ciência e Tecnologia do Vietnã.

Problema: 0 rastreamento de animais é um grande problema no setor agrícola. 0 objetivo principal é permitir o monitoramento regular da saúde dos animais; cuja consequência poderia levar a melhorias no bem-estar animal e na qualidade do produto, com um aumento significativo nos lucros. 0 sistema de reconhecimento de comportamento de vacas foi considerado a solução adequada para o monitoramento de vacas. Os requisitos para esse tipo de sistema são que ele seja barato, de alto desempenho e forneça dados em tempo real.

Objetivo: 0 objetivo da pesquisa é projetar um sistema de monitoramento de vacas em tempo real baseado em redes de sensores sem fio e no algoritmo de agrupamento K-means.

Metodologia: Um nó de sensor sem fio foi projetado para medir os dados de aceleração montados no colar usando um acelerômetro. Primeiramente, os dados coletados foram classificados em três classes de acordo com a função VeDBA (Vector of Dynamic Body Acceleration) usando o algoritmo K-means. Em seguida, os limites do VeDBA na etapa anterior foram usados para classificar novos dados.

Resultados: Três comportamentos (incluindo alimentar-se, deitar e ficar em pé) foram classificados em tempo real com acurácia de classificação em torno de $89 \%$.

Conclusão: 0 sistema proposto pode ser adaptado para o monitoramento de vacas em tempo real; a classificação do comportamento pode ser implementada no microcontrolador. Os resultados confirmaram a confiabilidade do sistema proposto.

Originalidade: a classificação comportamental pode ser implementada no microcontrolador pela primeira vez no monitoramento de vacas.

Limitações: apenas três comportamentos foram classificados no experimento.

Palavras-chave: monitoramento, sensor, K-means, redes de sensores sem fio, microcontrolador

\section{INTRODUCTION}

Livestock production is an essential source within the food supply chain, and animal monitoring is a significant problem in livestock. The primary purpose is to monitor the health of animals regularly. Consequently, animal welfare and product quality could be improved, leading to improved profit [1].

The traditional monitoring methods based on direct observation are not suitable for intensive farming, such as with big cow farms. A cow behavior recognition 
system was considered one of the promising solutions for cow monitoring [4-10]. The requirements for this kind of system are that it should be economical, high performance, and provide real-time data. Increased performance means the system could detect and classify cow behaviors accurately.

Due to its small size, low cost, and low power consumption, the sensor is convenient for measuring a variety of information and is widely used in modern agriculture. A monitor system based on accelerometers is a high-performance and economical approach for behavior activity monitoring [1-3, 11-17]. Using wireless sensor networks is a solution for the real-time requirement.

In this paper, a wireless sensor node was designed to measure the collar-mounted acceleration data of a cow using an accelerometer. Firstly, the collected data were classified into three classes based on the VeDBA (Vector of Dynamic Body Acceleration) feature using the K-means algorithm. Then, the thresholds for VeDBA in the previous step were used to classify new data. The proposed system, using wireless sensor networks, could be adapted to cow monitoring in real-time; the behavior classification could be implemented on the microcontroller with the accuracy of classification in the region of $89 \%$. Three behaviors could be classified using the proposed system, including feeding, lying, and standing.

\section{MATERIALS AND METHODS}

\subsection{Construction of wireless sensor networks for livestock behavior monitoring}

The proposed system uses two wireless sensor networks. The first one is a $2.4 \mathrm{GHz}$ wireless communication standard, which communicates individual mounted nodes to increase accuracy when determining status using various sensors. The $2.4 \mathrm{GHz}$ network is economical because it requires communication over a minimal distance (only internally). The second one is a wireless long-range sensor network (LoRa: Long Range). The advantage of LoRa is that it enables communication over very wide and far distances; the wireless links can achieve a sensitivity level of up to $-148 \mathrm{dBm}$. The energy requirements for LoRa communication are very small. Under test conditions, the power source from the battery can last up to 10 years. Each gateway of LoRa communication has the capacity to maintain communication with approximately 1000 LoRa terminals. The description of the location of the devices on the individual cow is shown in Figure 1. Two common positions of the devices are on the neck and on the leg of the cow. 


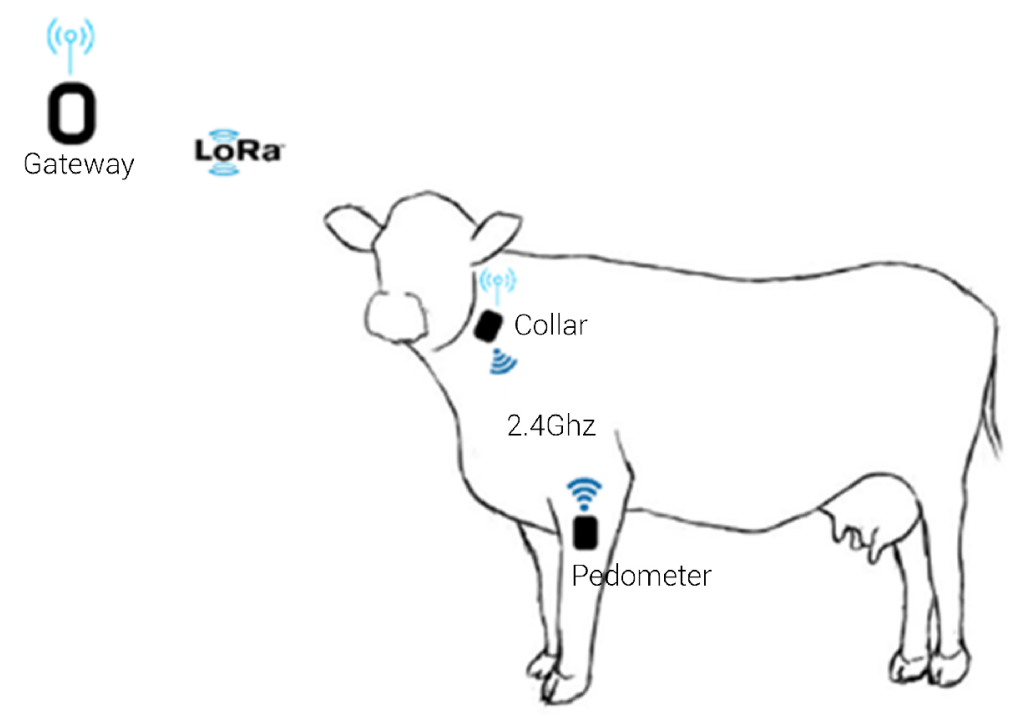

Figure 1. Describe the possible position of devices on an individual animal. Source: own work

\subsection{Measurement device and the cow in the experiment}

In this paper, we used the collar device, with dimensions $85 \times 60 \times 35 \mathrm{~mm}$ and weighs about 300g (Figure 2). It includes:1 Arduino Mega, Arduino Pro Mini, 1 module nRF24L01mini, 1 NEO-7M GPS module, 1 module LoRa Ra-02, 1 EEPROM AT24C512A, 1 DS1307, 1 module MPU6050.

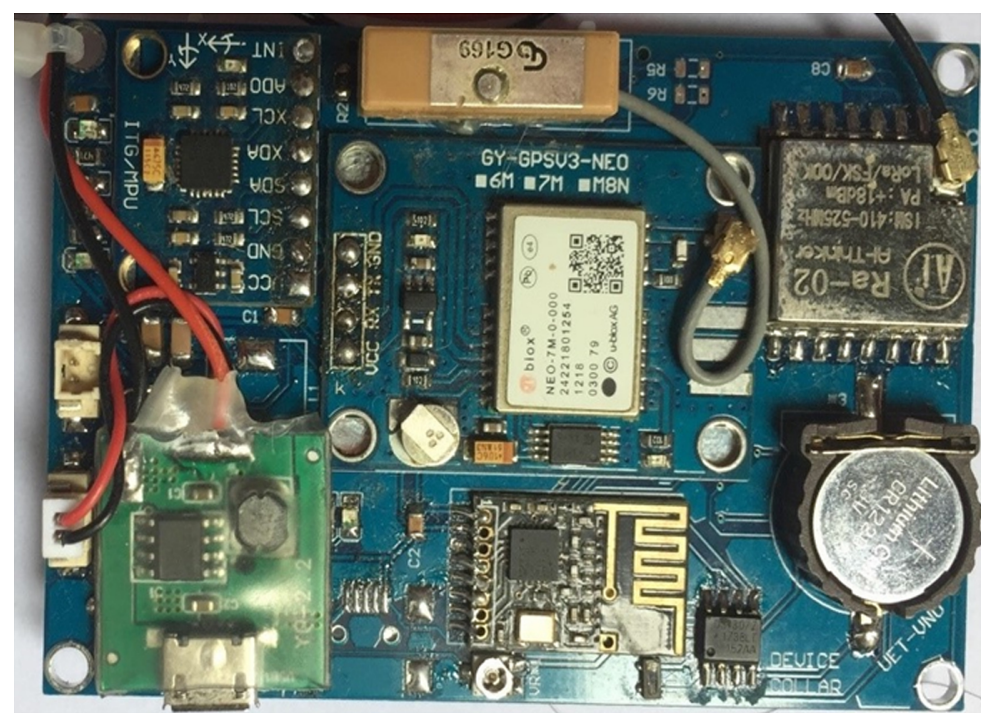

Figure 2. A photo of the collar device of a cow.

Source: own work 
6 Design of real-time cow behavior monitoring system based on wireless sensor networks and K-Mmeans clustering algorithm

Arduino Mega 2560 Pro is the central processor, controlling all peripheral devices and modules (with the exception of the LoRa Ra-02 module). Arduino Mega communicates with the MPU6050 module through the I2C interface along with two other modules: DS1307 and EEPROM AT24C512.

The NEO-7M GPS module connects and communicates with Arduino via UART communication. According to the manufacturer's information, data processing and analysis are done on the module itself.

The main module is the wireless nRF24L01mini module. This mini version is essentially no different from the regular version; the difference being that it is significantly smaller and much better suited for implementation within the Internet of things systems. This module communicates with the Arduino through the SPI standard. Using the SPI interface for this module likely guarantees a better transfer of data through the wireless environment. In data packets, sent via SPI protocol, there is no need to attach the device address; no bits are required to announce the mode to the module.

The DS1307 real-time module connects to Arduino Mega via I2C protocol. Using the pulse signal taken from Arduino Mega, it is reasonable to increase the synchronization between the internal counter in the Arduino and the counter of the module, which increases timing accuracy and reduces the workload for Arduino.

An EEPROM is connected to the Arduino via I2C interface; the Arduino can control the signal pulse through the SCL pin, so that the data, when converted to EEPROM for writing, is more synchronous, more stable, thereby ensuring the most stable data possible.

The power block maintains the power source for the entire collar device. It has components to protect the device, such as avoiding upstream current or overcharging the battery, causing a battery explosion that could cause injury. The power block has a design to add a charging port to charge the battery, making the device rechargeable without removing the outer shell.

Figure 3 shows the collar device attached on a cow. 


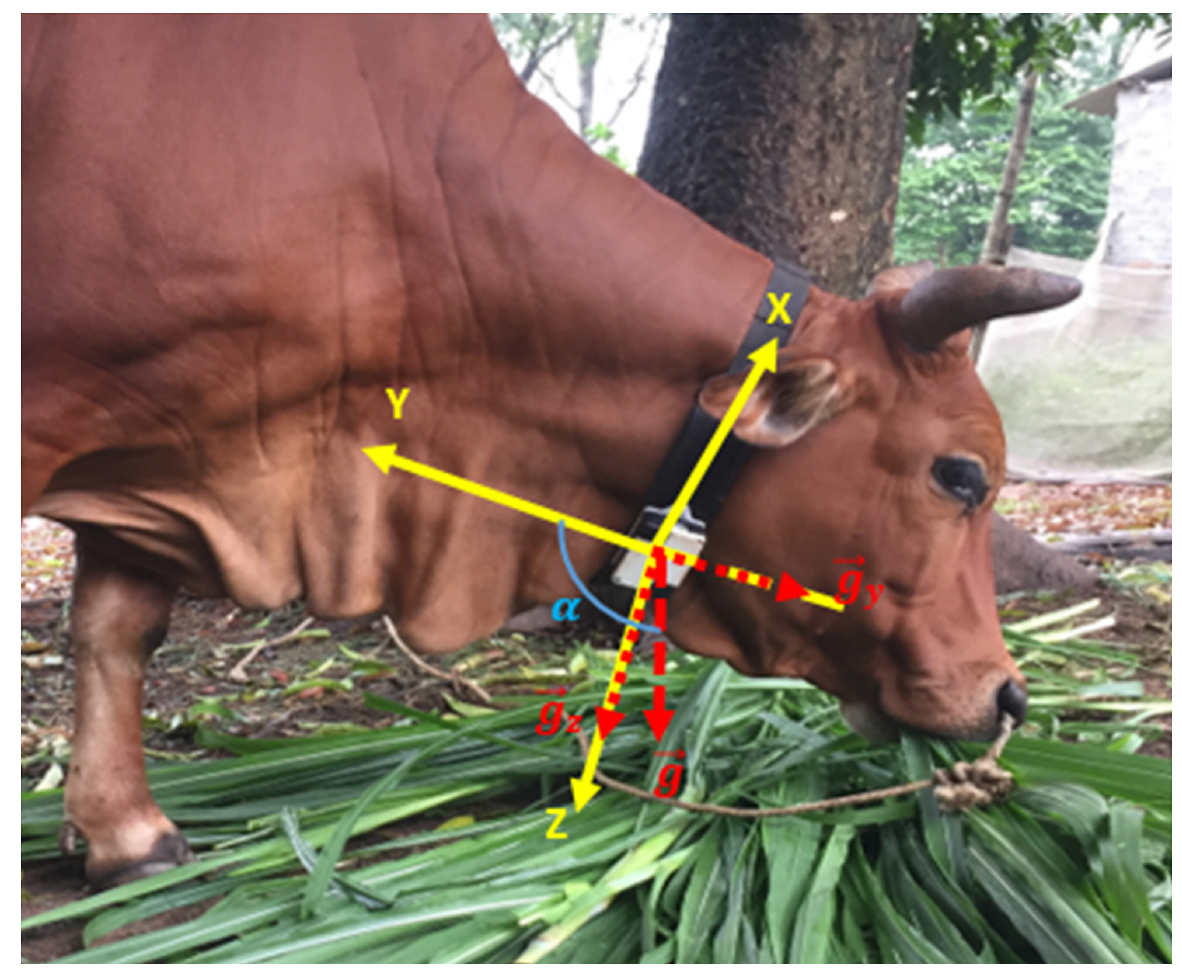

Figure 3. Cow with the collar device.

Source: own work

Vietnam Yellow Cattle (Figure 3) play an essential role in beef production in developing countries. These cows adapt to the monsoon-influence tropical climate such as that of Vietnam. Typically, the body mass of this species lies within the range of $180-300 \mathrm{~kg}$. The cows in this experiment are between $2-4$ years old.

\subsection{Classification of cow behavior using the K-means clustering algorithm}

There are three behaviors of the cow in the experiment:

- Feeding: The animal is eating in the eating area.

- Lying: The animal is in a lying down position.

- Standing: The animal stands on its four legs.

The collar device (Figure 2) collected accumulated acceleration data based on the accelerometer sensor. Figure 4 shows the accelerometer data samples under three axes corresponding to three behaviors: standing, lying, and feeding. 
8 Design of real-time cow behavior monitoring system based on wireless sensor networks and K-Mmeans clustering algorithm

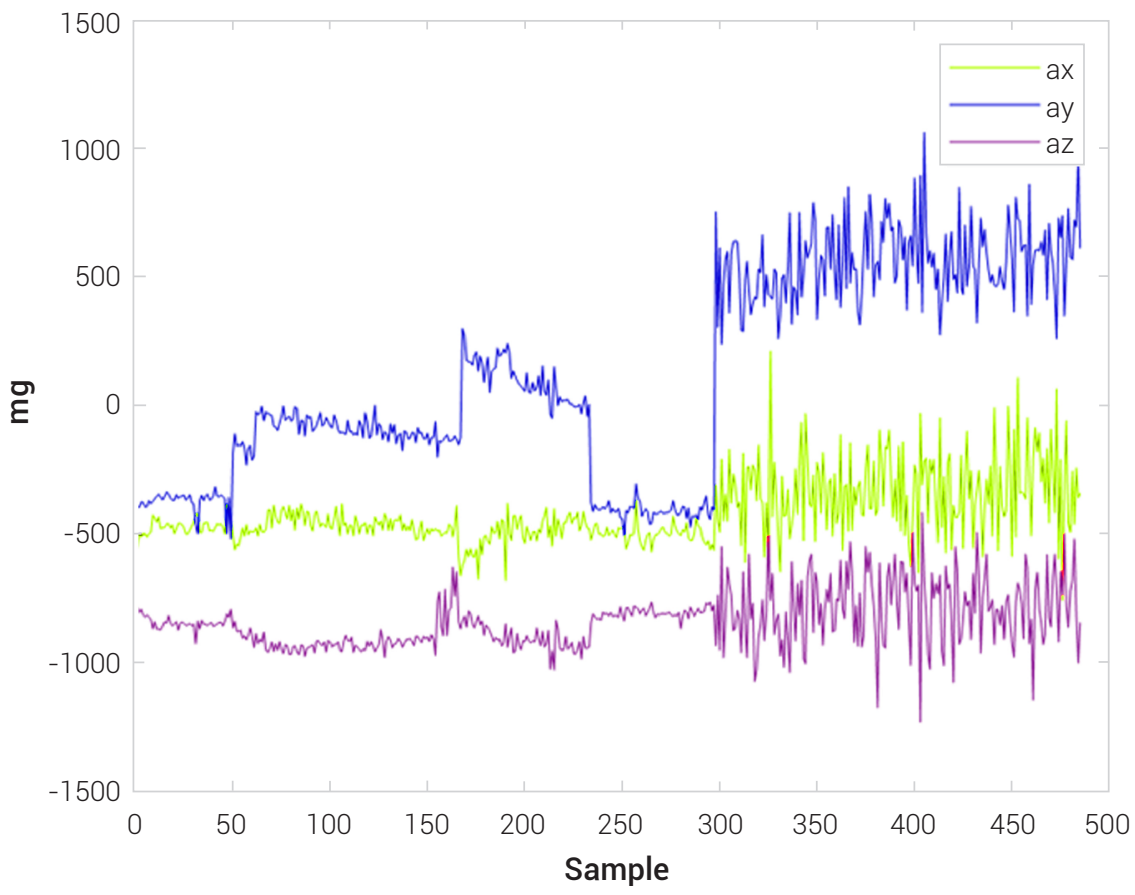

Figure 4. Acceleration data in 3 axes X, Y, Z (1 mg $\left.=0.001 \mathrm{~g}, 1 \mathrm{~g} \sim 9.8 \mathrm{~m} / \mathrm{s}^{2}\right)$. Flowchart for the K-means clustering is shown in Figure 5.

Source: own work

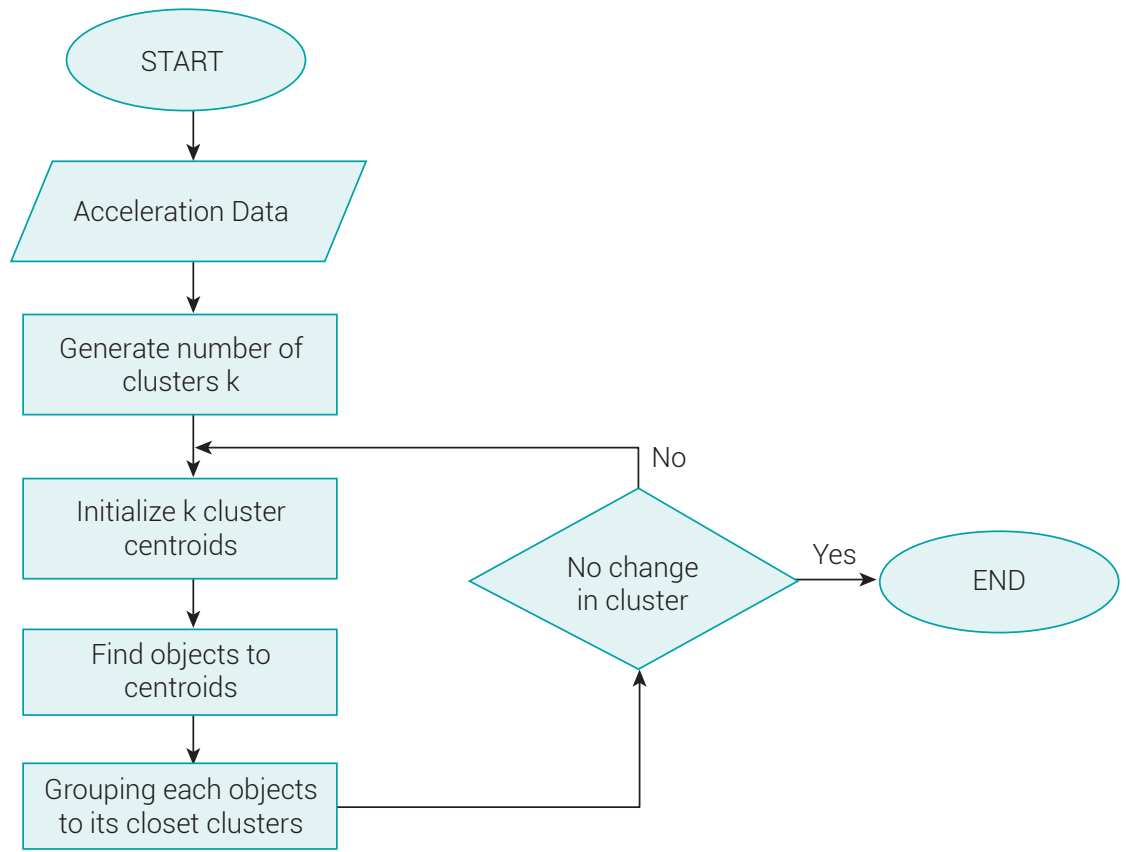

Figure 5. Flowchart for K-means clustering algorithm.

Source: own work 
The K-means algorithm is suitable for distinguishing cow behavior data because each data point (record) in this case represents only one behavior (in other words, there is only one label for a data point). The K-means algorithm conforms to a certain idea of behavior recognition in real-time and is simple to implement. Moreover, this algorithm guarantees convergence and easily adapts to new behavior data.

The main ideas are:

- Collecting acceleration data.

- Generating a number of clusters; 3 in this case for three behaviors.

- Finding centroids and grouping objects (acceleration data) to its closet clusters.

- $\quad$ Finding centroids and grouping objects based on the use of VeDBA.

The Constant threshold A for VeDBA was calculated; if the VeDBA value is greater than threshold $A$, it means acceleration data of high activity (feeding), the inverse corresponds to low activity.

Low activity behavior is lying or standing. We calculated threshold B for the static acceleration component of the y-axis (SCAY: Static Component of the Acceleration in the $\mathrm{Y}$-axis). If the value is greater than threshold $\mathrm{B}$, the behavior is determined to be standing; with the inverse being lying down.

To calculate VeDBA, we need the DBA (Dynamic Body Acceleration). The DBA represents the energy consumed by cattle in one direction.

$$
D B A_{t}=A_{i_{t}}=\left|A_{i_{t}}^{*}-\mu_{i_{t}}\right|
$$

where:

- $\mathrm{i}=\mathrm{x}, \mathrm{y}, \mathrm{z}$ represent the acceleration axes.

- $A_{i}$ is the static sensor value.

- $A_{i}^{*}$ is the value of acceleration data.

- $\quad \mu_{i_{t}}$ is the average value of acceleration data and is calculated by (2).

$$
\mu_{i_{t}}=\frac{1}{\text { win_size }} \sum_{\frac{\mathrm{t}_{\text {-win_size }}}{2}}^{\frac{\mathrm{t}+\text { win_size }}{2}} A_{i_{t}}^{*}
$$

We used the sliding window, which is calculated by (3) 


$$
d=\frac{(\mathrm{w}-1)}{2}
$$

ODBA is used to synthesize dynamic acceleration in the whole body. ODBA is identified in (4)

$$
O D B A=\left|A_{x}+A_{y}+A_{z}\right|
$$

VeDBA is also known as the motion acceleration synthesis vector. The ODBA and VeDBA parameters are commonly used to determine the cattle's energy consumption. VeDBA is calculated as in (5)

$$
V e D B A=\sqrt{A_{x}^{2}+A_{y}^{2}+A_{z}^{2}}
$$

SCAY, used to determine the replacement constant gravitational acceleration along the $y$-axis, is determined by (6)

$$
\overrightarrow{g_{y}}=g^{*} \cos (180-\beta)
$$

Our works were implemented in Matlab.

\section{RESULTS}

Figure 6 shows the calculation of the VeDBA feature as (5) of training data. It can be seen that for the feeding behavior (samples 300 to 490), the VeDBA values have a large range. However, lying and standing (all other samples) are still difficult to distinguish. Thus, we used SCAY characteristics. 


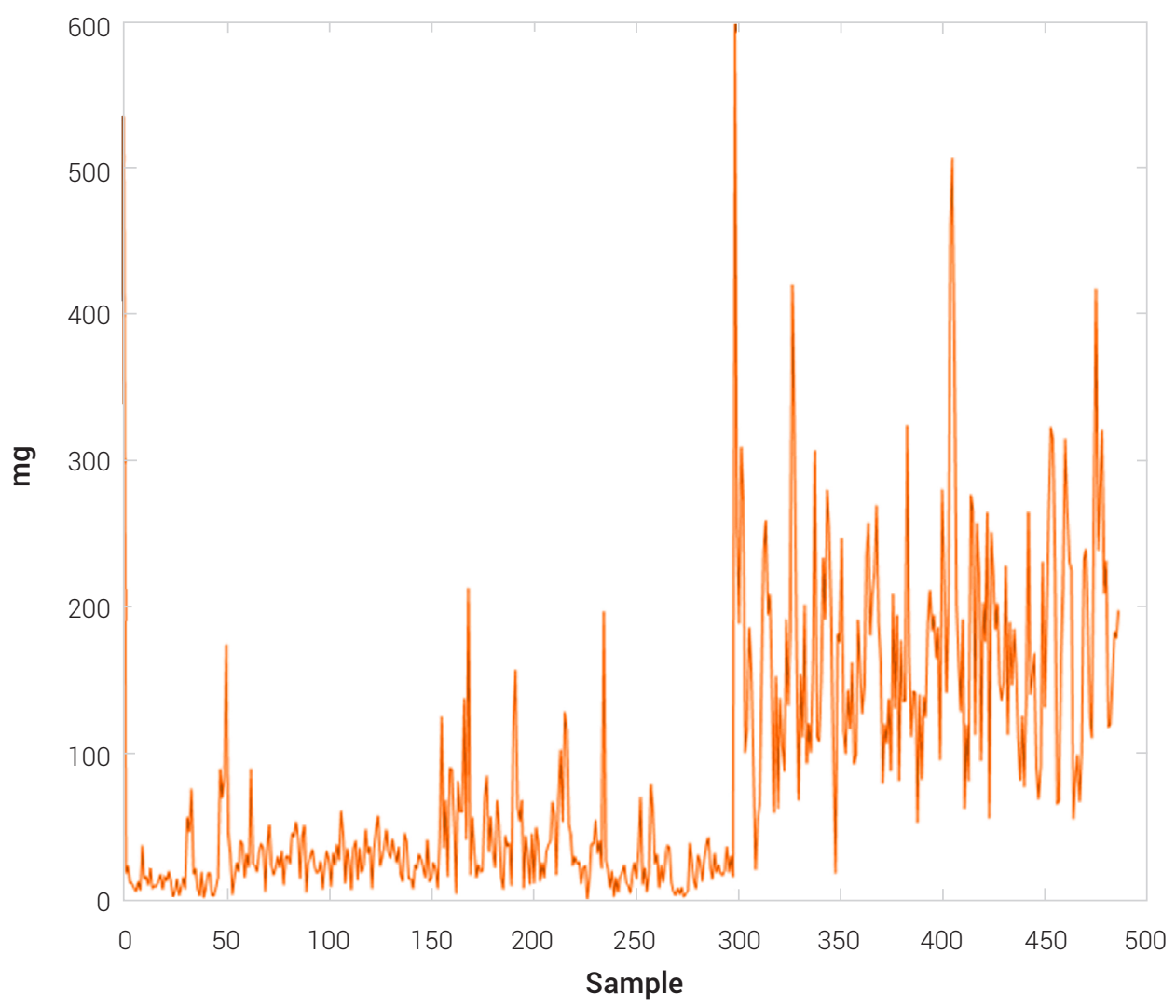

Figure 6. Characteristic of VeDBA feature.

Source: own work

Information about SCAY characteristics is described in Figure 7. With SCAY, three behaviors show some differences in values. Figure 8 shows the relationship between SCAY and VeDBA (horizontal axis) before using K-means. Figure 9 shows the relationship between SCAY and and VeDBA using K-means to find three different clusters. The three cluster centers are defined by:

Center of cluster $1=[-393.0000$ 17.3494]

Center of cluster $2=[-56.500033 .1097]$

Center of cluster $3=[563.2500$ 162.6249]

These values are then pre-loaded into the microcontroller's EPROM memory to execute the real-time classification of behaviors. It can be seen that when using K-means, it is possible to classify data into 3 clusters, but the corresponding behavior might still not be determined. Based on the dynamic properties of VeDBA and our methods (section 2.3), cluster 3 is feeding (dynamical largest), cluster 1 is lying, and cluster 2 is standing. 


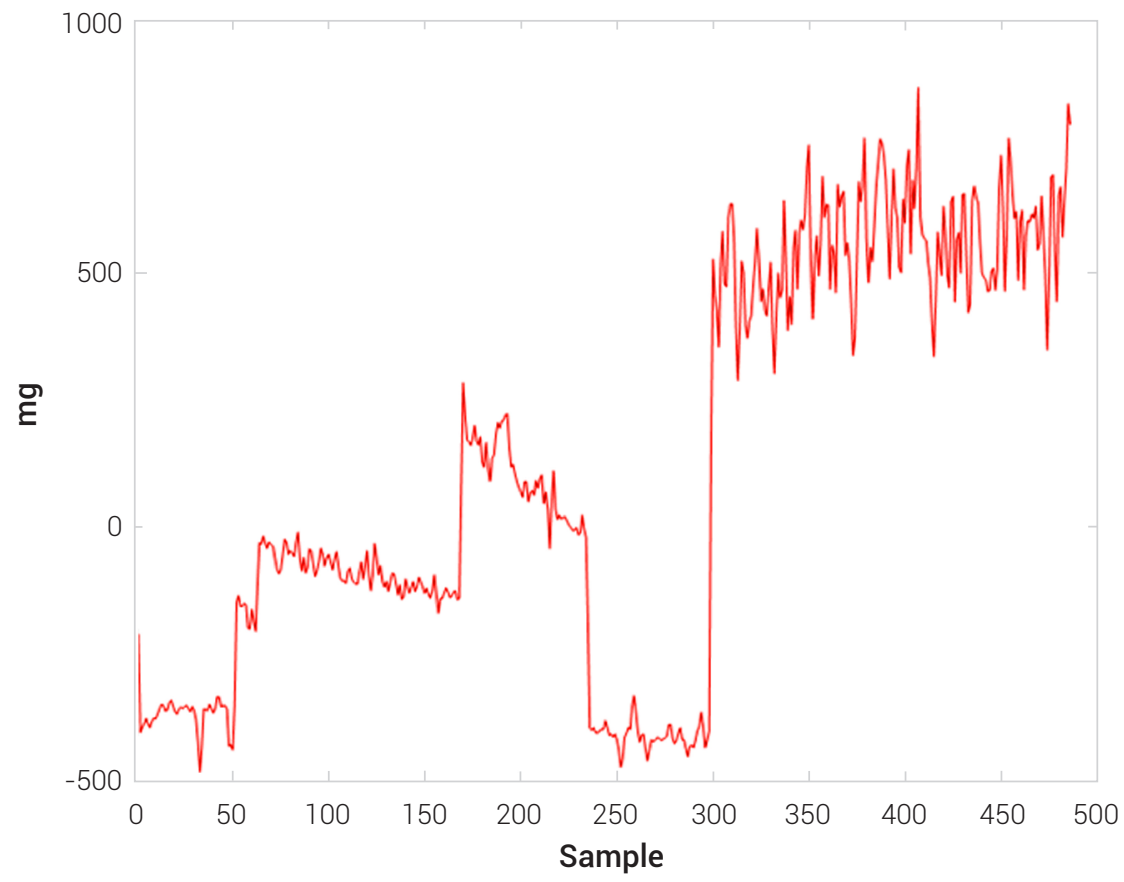

Figure 7. Opening cascade characteristic SCAY. Source: own work

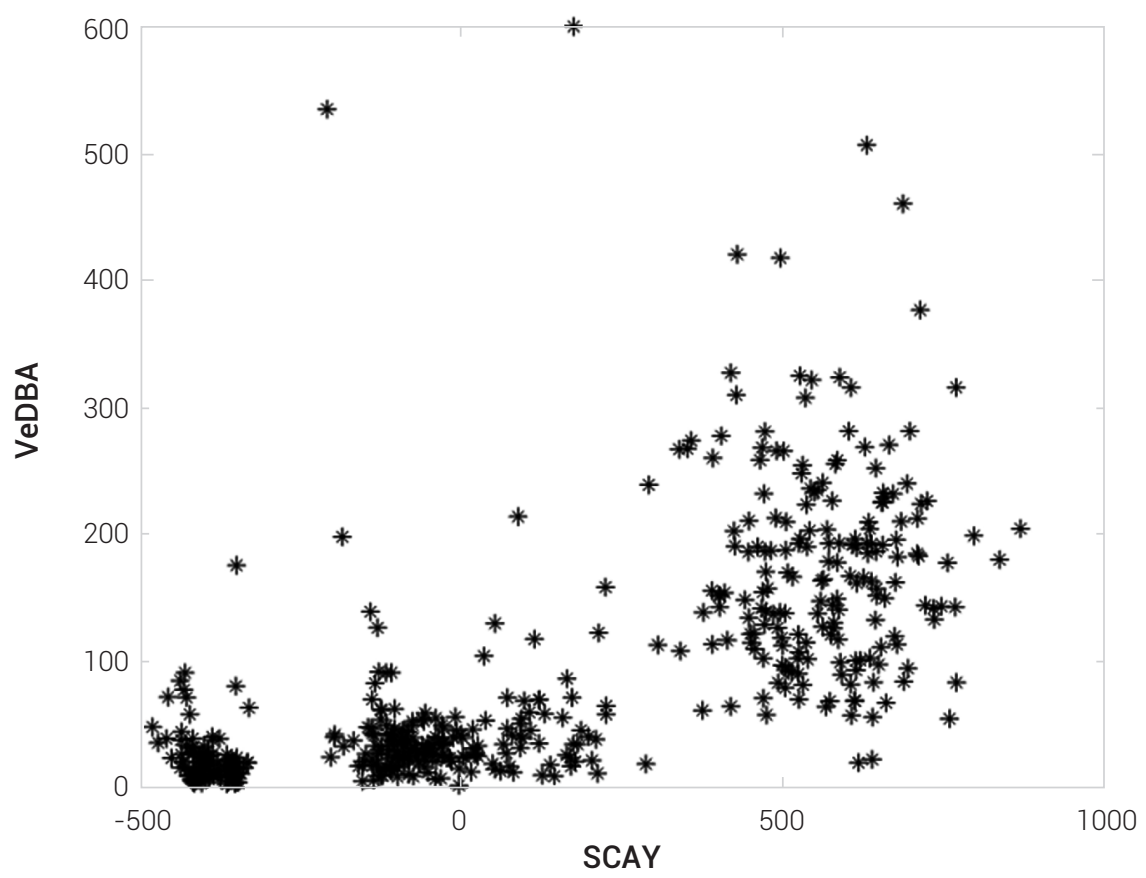

Figure 8. The relationship between SCAY (vertical axis) and VeDBA (horizontal axis). Source: own work 


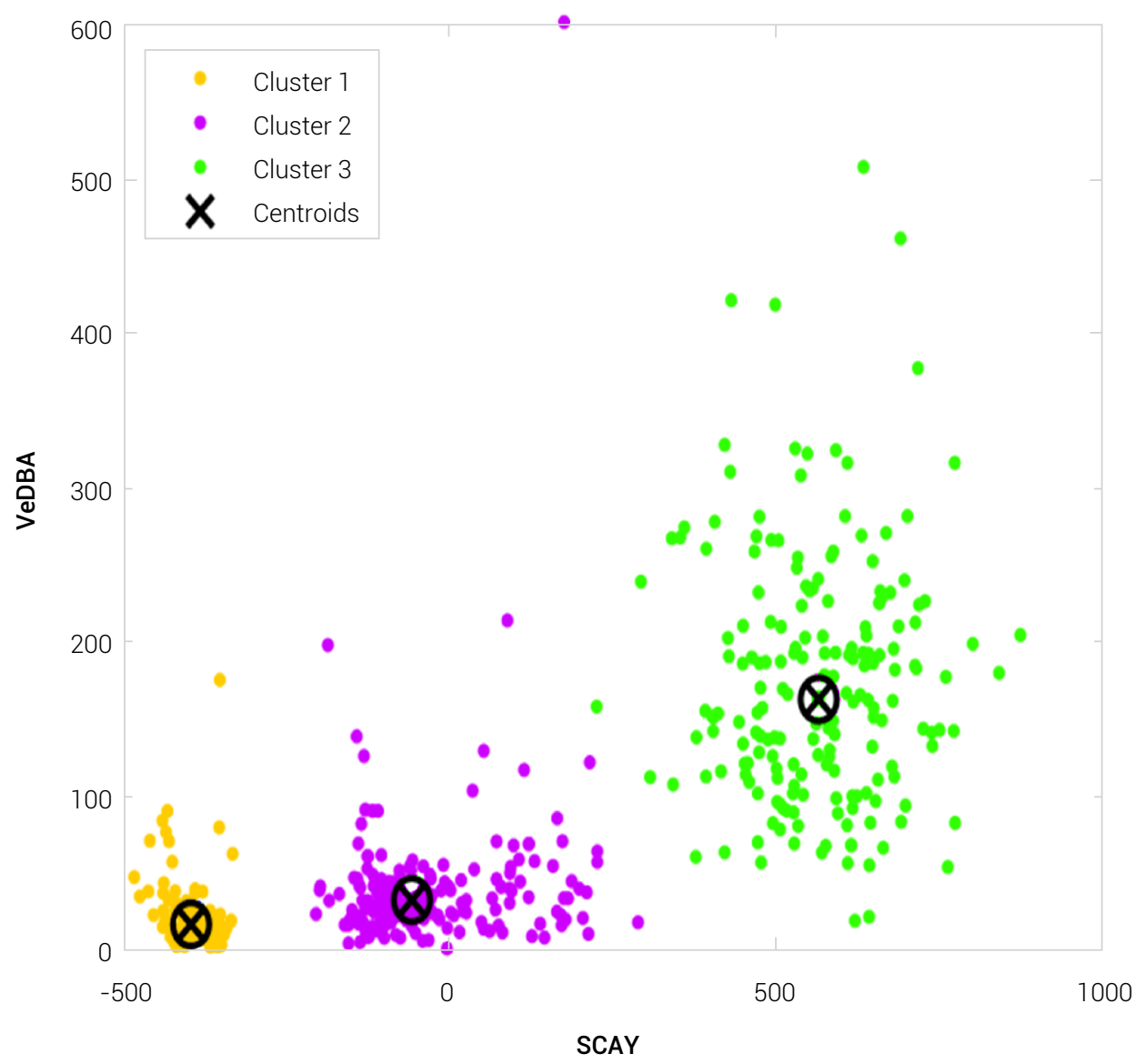

Figure 9. Relationship between SCAY (vertical axis) and VeDBA (horizontal axis) when using K-means with 3 clusters.

Source: own work

Figure 10 shows the calculation of the VeDBA feature with the test data as (5). Figure 11 shows the relationship between SCAY and VeDBA before using K-means to find three different clusters. The three cluster centers, defined by a training process, would be used to estimate three behaviors. 


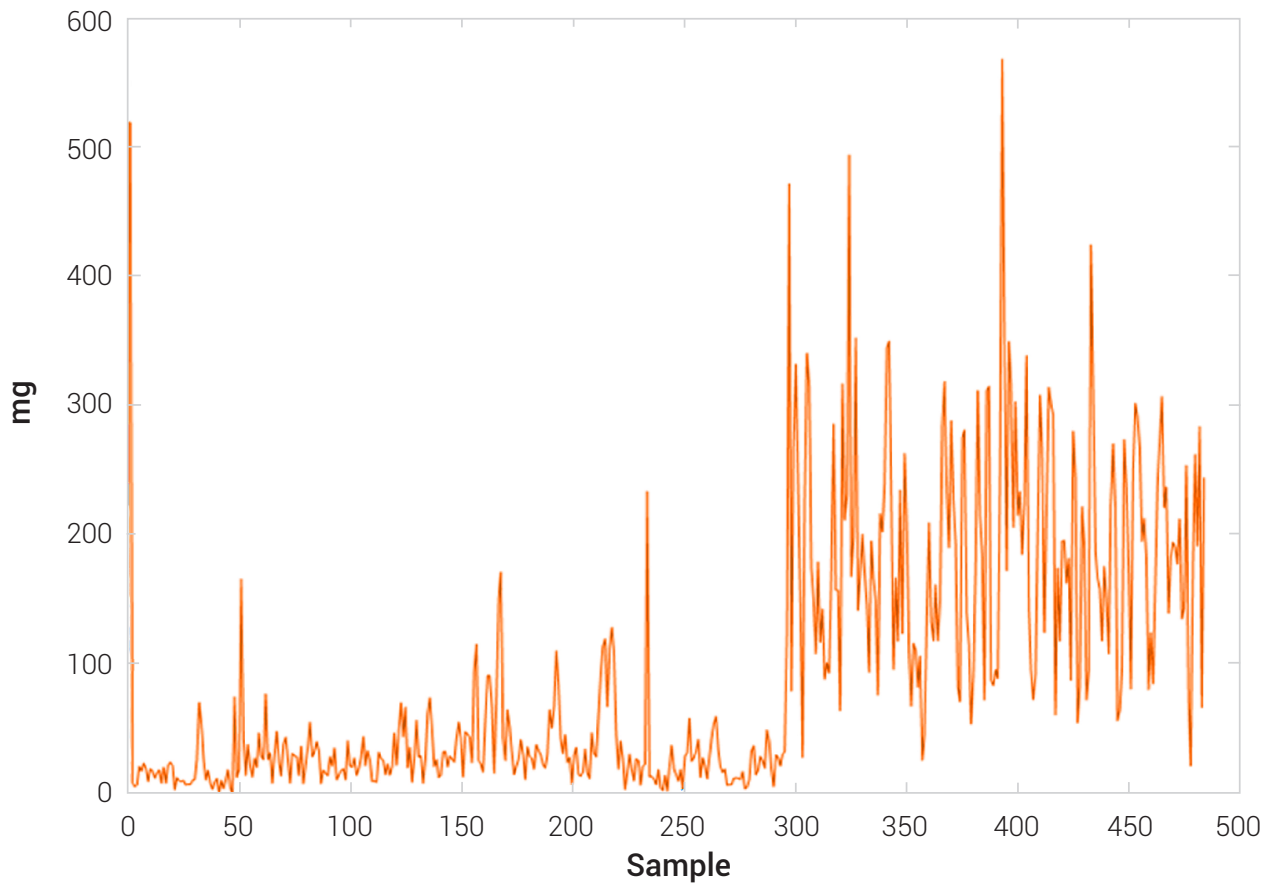

Figure 10. VeDBA of the test set. Source: own work

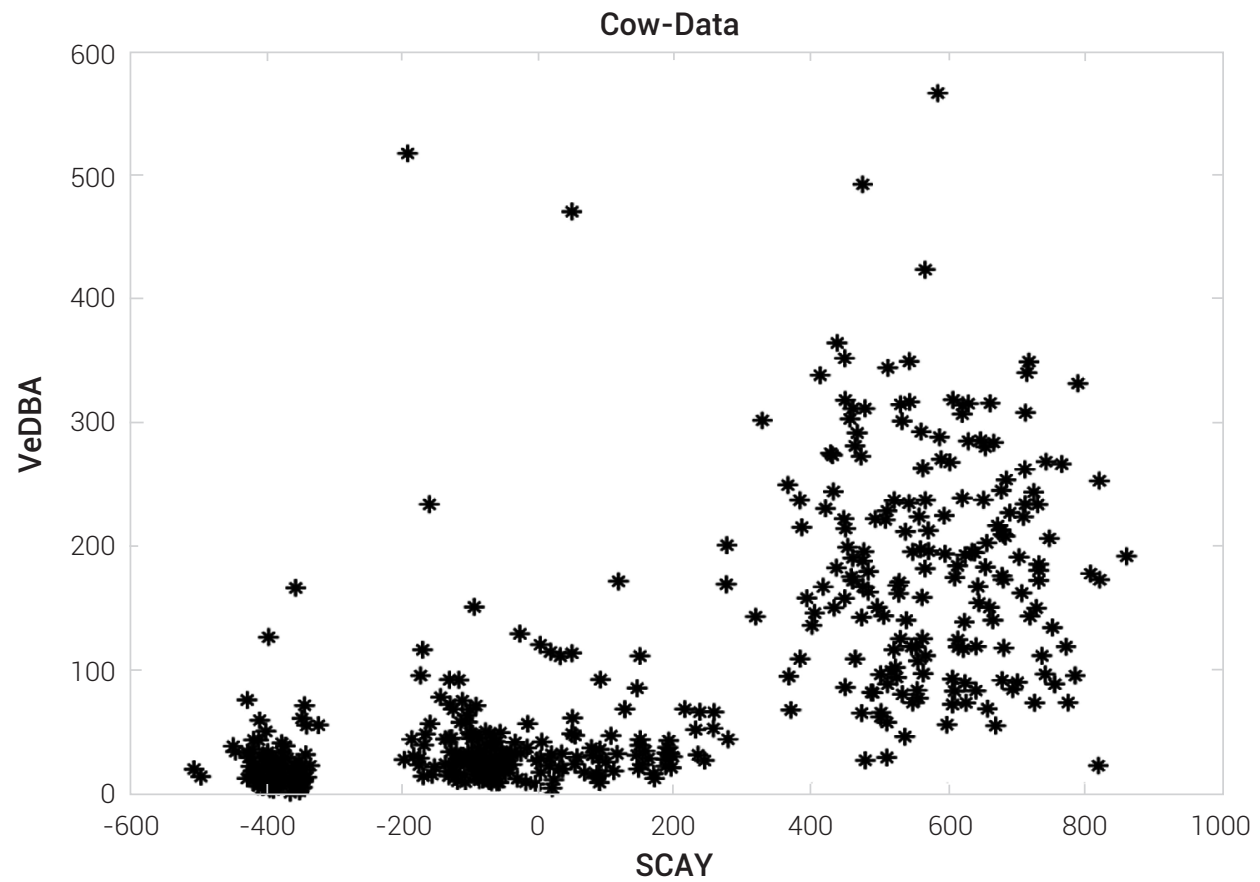

Figure 11. VeDBA - SCAY of the test set. Source: own work 
Figure 12 shows the estimated (up) and actual (down) identifiers of the three behaviors. Behavior index: 3 is feeding, 2 is standing, and 1 is lying. Some standing behaviors were misclassified to be lying behaviors. The accuracy of the estimation is $89.07 \%$.
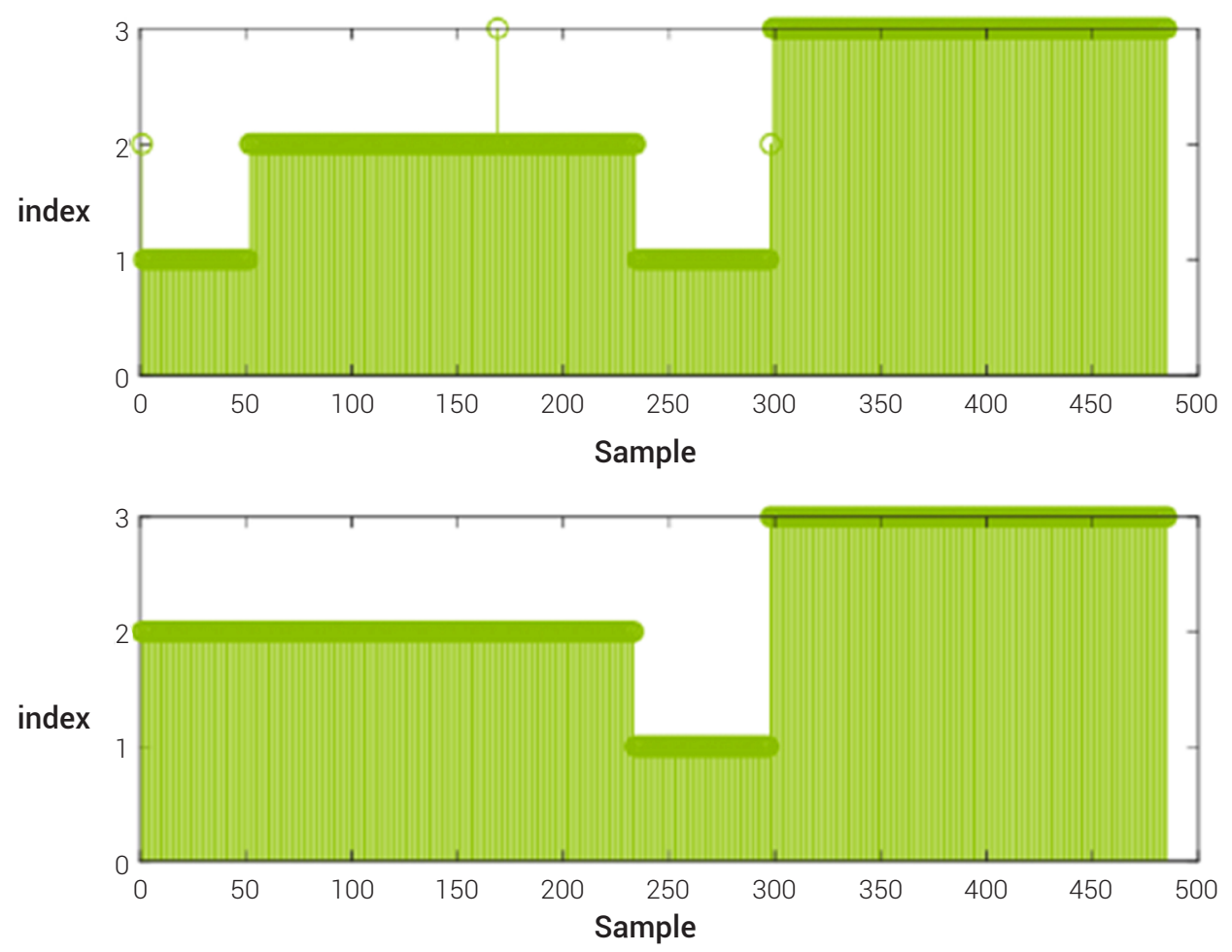

Figure 12. Estimated (up) and actual (down) behavior index ( 3 is feeding, 2 is standing, and 1 is lying).

Source: own work

Thus, we proposed the system to classify behavior on the microcontroller in real-time as follows:

- Step 1: Collect acceleration data under three axes every second (1 frame data obtained).

- $\quad$ Step 2: Estimate VeDBA and SCAY to obtain the space <VeDBA; SCAY>.

- Step 3: Calculate the distance to 3 center clusters (values of cluster centers in the space < VeDBA; SCAY> have been pre-loaded with the microcontroller).

- Step 4: Determine the minimum distance value (closet to the center of cluster), label the corresponding behavior.

- $\quad$ Step 5: Send classification results to the gateway. 


\section{DISCUSSION AND CONCLUSIONS}

Wang et al. [10] classified various cow behaviors based on the AdaBoost algorithm. The data in their work are leg-mounted acceleration data, sampled at $1 \mathrm{~Hz}$. The average accuracy of their system for predictions of cow behaviors was about $86 \%$, lower compared to this work's 89\%. However, our system currently classifies three behaviors, less than Wang et al. [10] with seven behaviors. If we extend the number of behaviors to classify, the overall performance might change as well.

Phung et al. [13] re-used a dataset from [10]. They proposed a system using a Gradient Boosted Decision Tree algorithm to classify seven behaviors with an overall accuracy of about $96 \%$, higher than our result. The performance of our work was also not better than $[3,13,14]$. As compensation, the advantage of our work compared to $[10,13]$ is cow behavior can be classified on the microcontroller to classify behavior in real-time. The trade-off is the lower performance of classification. Fortunately, the difference is not significant since we reached $89 \%$ accuracy. Our results in predicting three behaviors can be applied in real-time systems such as the proposal of $[18,19]$.

To ensure the node's long-term operation, the node's design should consider maintaining a constant input voltage and reducing energy consumption as much as possible. The node's size should be as small as possible and easy to install to minimize interference to the animals. In terms of communication, all nodes in the network use the same frequency to transmit and receive, which will cause channel competition and cause transmission failure to reduce the probability of successful transmission. Therefore, the capacity problem of wireless sensor network transmission with a single frequency is more prominent.

Energy management is equally important in software design. Energy consumption is required for sensor reading, data transmission and data processing. However, each link's energy consumption is different, so it is necessary to consider efficient programming to further reduce energy consumption comprehensively. Dynamic node management should also be implemented; when old nodes fail, new nodes join to ensure the orderly progress of the dynamic process. Additionally wireless network reprogramming should be supported to perform node remote control updates, and ensure a single node failure will not affect the reliability of the entire network.

Sensor installation problems need to be further improved. Sensor nodes may be used in extremely harsh environments (such as direct sunlight, rain, water mist, animal friction damage, etc.). Packaging and protection are essential.

This paper has proposed a real-time cow monitoring system based on wireless sensor networks and the K-means clustering algorithm to monitor three cow behaviors, including feeding, lying, and standing. The system is designed using the wireless sensor 
networks model, expanding the number of network nodes. The detection of behaviors is based on an accelerometer and K-means algorithm with a classification accuracy of about $89 \%$. In the future, we will classify more behaviors within our systems.

\section{ACKNOWLEDGEMENT}

Duc-Nghia Tran was supported by Vingroup Innovation Foundation (VinIF), Vingroup Big Data Institute (VinBigdata) under Domestic Postdoctoral Fellowship Program (scholarship number VINIF.2021.STS.21).

\section{REFERENCES}

[1] B. Robert, B. J. White, D. G. Renter, R. L. Larson, "Evaluation of three-dimensional accelerometers to monitor and classify behavior patterns in cattle," Comput. Electro. Agric., vol. 67, no. 1-2, pp. 80-84, Mar. 2009.

[2] C. Arcidiacono, S. M. Porto, M. Mancino, G. Cascone, "A threshold-based algorithm for the development of inertial sensor-based systems to perform real-time cow step counting in free-stall barns," Biosyst. Eng., vol. 153, pp. 99-109, Nov. 2016.

[3] C. Arcidiacono, S. M. C. Porto, M. Mancino, G. Cascone, "Development of a threshold-based classifier for real-time recognition of cow feeding and standing behavioral activities from accelerometer data," Comput. Electro. Agric., vol. 134, pp. 124-134, Jan. 2017.

[4] C. W. Maina, "IoT at the Grassroots-Exploring the Use of Sensors for Livestock Monitoring," in Ist-Africa Week, 2017, pp. 1-8.

[5] J. A. V. Diosdado, Z. E. Barker, "Classification of behavior in housed dairy cows using an accelerometer-based activity monitoring system," Anim. Biotelemetry, vol. 3, pp. 1-14, Jun. 2015.

[6] E. S. Nadimi, H. T. Søgaard, "Observer Kalman filter identification and multiple-model adaptive estimation technique for classifying animal behavior using wireless sensor networks," Comput. Electro. Agric., vol. 68, pp. 9-17, Aug. 2009.

[7] K. O'Driscoll, L. Boyle, A. Hanlon, "A brief note on the validation of a system for recording lying behavior in dairy cows," Appl. Anim. Behav. Sci., vol. 111, pp. 195-200, May 2008.

[8] M. S. Shahriar, D. Smith, "Detecting heat events in dairy cows using accelerometers and unsupervised learning," Comput. Electro. Agric., vol. 128, pp. 20-26, Oct. 2016. 
Design of real-time cow behavior monitoring system based on wireless sensor networks and K-Mmeans clustering algorithm

[9] J. M. Talavera, L. E. Tobón, J. A. Gómez, M. A. Culman, J. M. Aranda, D. T. Parra, et al., "Review of IOT applications in agro-industrial and environmental fields," Comput. Electro. Agric., vol. 142, pp. 283-297, Nov. 2017.

[10] J. Wang, Z. He, "Development and validation of an ensemble classifier for real-time recognition of cow behavior patterns from accelerometer data and location data," PLoS One, vol. 13, Aug. 2018.

[11] B. D. Robért, B. J. White, D. G. Renter, R. L. Larson, "Determination of lying behavior patterns in healthy beef cattle by use of wireless accelerometers," Am. J. Vet. Res.; vol. 72, pp. 467-473, Apr. 2011.

[12] J. Wang, Z. He, J. Ji, K. Zhao, H. Zhang, "IoT-based measurement system for classifying cow behavior from tri-axial accelerometer," Cienc. Rural, vol. 49, pp. 1-13, Mar. 2019.

[13] C. P. K. Phung, D. T. Tran, V. T. Duong, H. T. Nguyen, D. N. Tran, "The new design of cows' behavior classifier based on acceleration data and proposed feature set," Math. Biosci. Eng., vol. 17, no. 4, pp. 2760-2780, March 2020

[14] P. Martiskainen, M. Jarvinen, "Cow behavior pattern recognition using a three-dimensional accelerometer and support vector machines," Appl. Anim. Behav. Sci., vol. 119, pp. 32-38, Jun. 2009.

[15] J. A. Vázquez Diosdado, Z. E. Barker, H. R. Hodges et al., "Classification of behavior in housed dairy cows using an accelerometer-based activity monitoring system," Anim. Biotelemetry, vol. 3, no. 15, Jun. 2015.

[16] D. Berckmans, "Automatic on-line monitoring of animals by precision livestock farming," in ISAH, Saint-Malo, France, 2004, pp. 27-30

[17] L. Atallah, B. Lo, R. King, G. Yang, "Sensor positioning for activity recognition using wearable accelerometers," IEEE Trans. Biomed. Circ. Syst., vol. 5, pp. 320-329, Sep. 2011.

[18] C. P. K. Phung, T. K. Nguyen, D. C. Nguyen, D. N. Tran, D. T. Tran, "Classification of cow's behaviors based on 3-DoF accelerations from cow's movements," Int. J. Electr. Comput. Eng., vol. 9, pp. 1656-1662, 2019.

[19] Q. T. Hoang, C. P. K. Phung, T. N. Bui, T. P. D. Chu, D. T. Tran, "Cow behavior monitoring using a multidimensional acceleration sensor and multiclass SVM," Int. J. Mach. Learn. Networked Collab. Eng., vol. 2, pp. 110-118, 2018. 